\title{
One pot synthesis of nitriles from aldehydes and hydroxylamine hydrochloride using sodium sulphate (anhyd) and sodium bicarbonate in dry media under microwave irradiation
}

\author{
Sharwan K. Dewan*, Ravinder Singh, and Anil Kumar \\ Department of Chemistry, M.D. University Rohtak-124001 (Haryana) India \\ E-mail: sharwandewan@rediffmail.com
}

\begin{abstract}
A rapid and facile one pot synthesis of nitriles has been carried out in high yields from the corresponding aldehydes and hydroxylamine hydrochloride in the presence of environmentally benign sodium sulphate (anhyd) and sodium bicarbonate catalysts in dry media under microwave irradiation.
\end{abstract}

Keywords: Nitriles, aldehydes, hydroxylamine hydrochloride, $\mathrm{Na}_{2} \mathrm{SO}_{4}$ (anhyd), $\mathrm{NaHCO}_{3}, \mathrm{MW}$

\section{Introduction}

Nitriles are widely used for transformation into amides, amines, esters, carboxylic acids etc. ${ }^{1}$ Hence they have been used as intermediates for the synthesis of fine chemicals such as agricultural chemicals, dyes and medicines. ${ }^{2}$ One of the most general methods for the synthesis of nitriles is the nucleophilic substitution reaction of alkyl halides with metal cyanides. The method is, however, inconvenient because of high toxicity of metal cyanides and troublesome handling. Consequently, other methods such as the dehydration of primary amides ${ }^{3}$ or aldoximes $^{4-7}$ have attracted attention. It is known that dehydration of aldoximes into nitriles can be achieved by using a variety of reagents like triethylamine/sulfur dioxide, ${ }^{4}$ zeolites, $^{5}$ sulfurylchloride fluoride, ${ }^{6}$ sulfuryl chloride ${ }^{7}$ etc. but many of these suffer from limitations such as high toxicity, vigorous reaction conditions, unsatisfactory yields, tedious work up and use of large excess of reagents. We have recently reported a rapid synthesis of nitriles in high yields from aldoximes using silica gel ${ }^{8 a}$ and one-pot synthesis of nitriles from aldehydes and hydroxylamine hydrochloride using silicagel, Mont K-10, and KSF catalysts in dry media under microwave irradiation. ${ }^{8 b}$ Some rapid procedures for one pot synthesis of nitriles have been described using formic acid ${ }^{9}$ and potassium peroxy monosulfate ${ }^{10}$ but whereas the first method suffers from undesirable action of formic acid that can affect acid-sensitive aldehydes, the second suffers from the undesirable oxidation of some functional groups. So, there exists a need 
for developing rapid and facile methods for one pot synthesis of nitriles. As part of our interest in rapid synthetic transformations. ${ }^{11}$ we report herein a rapid one pot synthesis of nitriles aldehydes and hydroxylamine hydrochloride using sodium sulphate (anhyd) and sodium bicarbonate in dry media, which we thought would catalyze both the oxime formation and the consequent nitrile formation steps (Scheme 1).

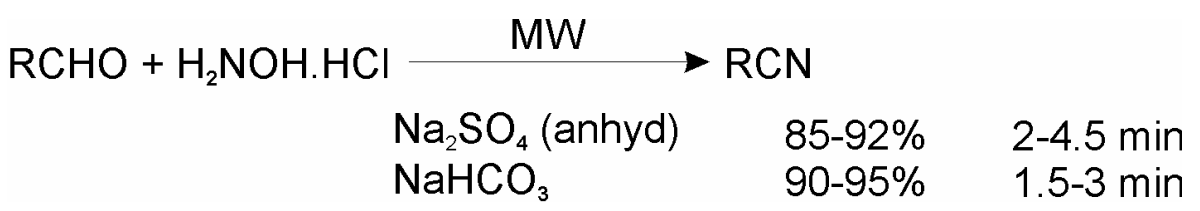

\section{Scheme 1}

There has been a growing interest over the past few years to carry out organic reactions over heterogenous catalysts, because of simple set ups and work-ups, lesser chemical degradation, higher product purity and chemical yields. ${ }^{12}$ Microwave activation as a nonconventional energy source especially when coupled to dry-media conditions has become a very popular and useful technology in organic chemistry in terms of reduced reaction times, enhanced product purity and chemical yields in an environmentally friendly approach called green chemistry. ${ }^{13}$ Dry media conditions are particularly suitable for doing away with the safety hazards usually associated with low-boiling solvents under microwave irradiation.

Investigations were initiated with 3,4-dimethoxybenzaldehyde being chosen as a model compound. It was condensed with hydroxylamine hydrochloride in presence of sodium sulphate (anhyd) under varying levels of irradiation (80 - $800 \mathrm{~W}$ ). The best yield of $85 \%$, was obtained at $560 \mathrm{~W}$ after 4.5 minutes of irradiation. Hence, all the subsequent reactions were carried out under these reaction conditions. A variety of substituted aromatic aldehydes (1-6), quinoline carboxaldehyde (8), pyridine carboxaldehyde (9) and an aliphatic aldehyde (10) were included. The reactions were monitored by TLC. The products yields and reactions times are collected in the Table. All the products are known compounds and were identified on the basis of their spectroscopic analyses and by direct comparison of their m.p. with those of the authentic samples. ${ }^{8}$ The products were obtained in more than 95\% purity as determined by ${ }^{1} \mathrm{H}$ NMR and were further purified by chromatography.

As can be seen, the nitriles were formed rapidly in high yields of $85-92 \%$ yield within 1-3 min. Next we carried out one pot synthesis of nitriles using $\mathrm{NaHCO}_{3}$ as the catalyst. The results obtained are collected in Table1. The nitriles were obtained in slightly better yields in 90-95\% under identical reaction conditions as compared to those obtained with sodium sulphate (anhyd). It should be noted that the nitriles were formed in only 2-3\% yield under identical reaction conditions in the absence of the catalysts, thereby confirming the role of the catalysts in the reactions. 
Table 1. One pot synthesis of nitriles from aldehydes and hydroxylamine hydrochloride using sodium sulphate (anhyd) and sodium bicarbonate at $560 \mathrm{~W}$

\begin{tabular}{|l|l|c|c|c|c|}
\hline \multirow{2}{*}{ Entry } & \multicolumn{1}{|c|}{ Product } & \multicolumn{2}{|c|}{$\mathrm{Na}_{2} \mathrm{SO}_{4}$ (anhyd) } & \multicolumn{2}{c|}{$\mathrm{NaHCO}_{3}$} \\
\cline { 3 - 6 } & & $\begin{array}{c}\text { Isolated } \\
\text { yield (\%) }\end{array}$ & $\begin{array}{c}\text { Time } \\
\text { (min.) }\end{array}$ & $\begin{array}{c}\text { Isolated } \\
\text { yield (\%) }\end{array}$ & Time (min.) \\
\hline 1. & $\begin{array}{l}\text { 3,4-Dimethoxy } \\
\text { benzonitrile }\end{array}$ & 85 & 4.5 & 93 & 3.0 \\
\hline 2. & 4-Methoxy benzonitrile & 92 & 3.5 & 95 & 1.5 \\
\hline 3. & 2-Hydroxy benzonitrile & 90 & 3.5 & 90 & 1.5 \\
\hline 4. & 4-Hydroxy benzonitrile & 89 & 4.0 & 90 & 1.5 \\
\hline 5. & 4-Nitro benzonitrile & 86 & 2.0 & 94 & 1.5 \\
\hline 6. & $\begin{array}{l}\text { 3-4-5, trimethoxy } \\
\text { benzonitrile }\end{array}$ & 89 & 3.0 & 90 & 2.5 \\
\hline 7. & Trans-cinnamonitrile & 90 & 2.0 & 91 & 2.0 \\
\hline 8. & Quinoline-2-carbonitrile & 89 & 2.0 & 91 & 1.5 \\
\hline 9. & 2-Ethyl-4-cyano pyridine & 90 & 3.0 & 93 & 2.5 \\
\hline
\end{tabular}

In summary, we have demonstrated the use of the inexpensive, easy to handle and environmentally benign sodium sulphate (anhyd) and sodium bicarbonate in rapid one pot synthesis of nitriles from aldehydes and hydroxylamine hydrochloride in high yields.

\section{Experimental section}

General Procedures. Melting points were determined in open capillaries on an electrically heated metal block and are uncorrected. ${ }^{1} \mathrm{H}$ NMR $\left(\mathrm{CDCl}_{3}\right)$ spectra were recorded on a Jeol FX90Q instrument using TMS as an internal standard. IR spectra were recorded on a PerkinElmer 782 spectrophotometer. TLC was carried out on silica gel G plates with a benzene/ethyl acetate (4:1) system. 
Typical experimental procedure: 3,4-Dimethoxybenzaldehyde (166 mg, I mmol), hydroxylamine hydrochloride (105 mg, $1.2 \mathrm{mmol}$ ) were mixed with sodium sulphate(anhyd) (1 g) or $\left(\mathrm{NaHCO}_{3}, 1 \mathrm{~g}\right)$ and taken up in an Erlenmeyer flask (25 mL) and irradiated at $560 \mathrm{~W}$ for 4 min in an unmodified domestic microwave oven (Kenstar OM-9925E, $800 \mathrm{~W}$, operating at 2450 $\mathrm{MHz})$. The flask was taken out, cooled and ether $(15 \mathrm{~mL})$ was added. The catalyst was filtered off and the resultant solution evaporated to give a residue which was purified by chromatography using benzene/ethyl acetate (4:1) as eluent to afford the desired nitrile (85\% yield with $\mathrm{Na}_{2} \mathrm{SO}_{4}$ and 93\% yield with $\left.\mathrm{NaHCO}_{3}\right):{ }^{1} \mathrm{H}$ NMR $\left(\mathrm{CDCl}_{3}\right), 3.8$ (s, 3H, -OCH3), 3.9 (S, 3H, -OCH3) 6.9 (m, 1H, ArH), 7.0 (m, 2H, ArH); IR (neat) 2940 (C-H str.) 2220 (C $\equiv N$ str.), 1610, 1540 \& 1450 (C-C str.); m.p. $62.5^{\circ} \mathrm{C}$, lit $^{8} 63^{\circ} \mathrm{C}$.

\section{Acknowledgements}

We thank Prof. A.J. Bellamy for inspiration and Mr. Yashwant for a gift of the microwave oven used in this investigation and A.K. thanks UGC, New Delhi for an award of JRF.

\section{References}

1. Cohen, M.A.; Sawden, J.; Turner, N.J. Tetrahedron Lett. 1990, 31,7223.

2. Fabiani, M.E. Drug News Perspect 1999,12, 207.

3. Baxendale, I.R.; Ley, S.V.; Sneddon, F.H. Synlett 2002, 5, 775 and references therein.

4. Olah, G.A.; Vankar, Y.D. Synthesis 1978, 702.

5. Rao, M. Narayana.; Kumar, P.; Garyali, K. Org. Prep. Proceed. Int. 1989,21,230.

6. Olah, G.A.; Narang, S.C.; Garcia-Luma A. Synthesis 1980, 659.

7. Krynitsky, J.A.; Carhart, H.M. Org Synth. Coll. Vol IV 1963, 436.

8. (a) Dewan, S.K.; Singh, R. Synth. Commun. 2003, 33, 385. (b) Dewan, S.K.; Singh, R.; Kumar, A. Synth. Commun, 2004, 2025.

9. Feng, J.C.; Lin, B.; Dai, L.; Bian, N.S. Syn. Commun. 1998, 28, 3765.

10. Bose, D.S.; Narsaiah, A.V. Tetrahedron Lett. 1998, 39, 6533.

11. (a) Dewan, S.K.; Singh, R. Synth. Commun. 2003, 33, 3085. (b) Dewan, S.K.; Singh, R. Orient J Chem. 2002, 18, 601. (c) Dewan, S.K.; Singh, R. Ind. J Het. Chem. 2003, 12, 287.

12. (a) Tanaka, K.; Toda, F. Chem. Rev. 2000, 100, 1025. (b) Smith, K. Ed. Solid Supports and Catalysts in Organic Synthesis, Ellis Horwood and PTR Prentice Hall: New York, 1992. (c) Villemin, D.; Vlieghe, X. Sulfur Lett. 1998, 21, 191, and references therein (d) Laszlo, P. Preparative Chemistry using Supported Reagents, Academic Press, 1987. (e) Dewan, S.K.; Varma, U.; Malik, S.D. J. Chem. Res. (S) 1995, 21 and references therein.

13. Loupy, A.; Petit, A.; Hamelin, J.; Texier-Boulett, F.; JacKqualt, P.; Maine, D. Synthesis 1998, 1, 213. 